\title{
Correction to: Heat attenuation and nutrient delivery by localized upwelling avoided coral bleaching mortality in northern Galapagos during 2015/2016 ENSO
}

\author{
Bernhard Riegl $^{1}{ }_{(\mathbb{D})} \cdot$ Peter W. Glynn $^{2} \cdot$ Stuart Banks $^{3}$ - Inti Keith ${ }^{4}$. \\ Fernando Rivera $^{5}$ - Mariana Vera-Zambrano ${ }^{3}$. Cecilia D'Angelo ${ }^{6}$. \\ Jörg Wiedenmann ${ }^{6}$
}

Published online: 24 May 2019

(C) Springer-Verlag GmbH Germany, part of Springer Nature 2019

\section{Correction to: Coral Reefs \\ https://doi.org/10.1007/s00338-019-01787-8}

In the original print, the addresses of authors Wiedenmann and D'Angelo were incomplete and the acknowledgements failed to mention the Galapagos National Park and CDRS publication number. These errors are corrected herein.

Acknowledgements We are grateful to The Galapagos National Park Directorate (GNPD) for their support of this research. This publication is Contribution Number 2263 of the Charles Darwin Foundation for the Galapagos Islands. Funding by Darwin Initiative,
Conservation International-Ecuador (Galapagos program and CIETPS), The Leona M. and Harry B. Helmsley Charitable Trust, and the Walton Family Foundation to the Eastern Tropical Pacific Seascape Transition Phase (CI 2014-560) is greatly appreciated. P.W. Glynn acknowledges U.S. National Science Foundation support, Grants OCE-1447306, OCE-9314798 and earlier awards. Authors thank K. Collins and S. Steiner for assistance with field work. Cptn. Pico and the crew of RV Queen Mabel were a steadfast support through all kinds of weather. The contribution of JW and Cd'A was funded by NERC (NE/K00641X/1) and European Research Council under the European Union's Seventh Framework Program (FP/20072013/ERC Grant Agreement No. 311179).

Publisher's Note Springer Nature remains neutral with regard to jurisdictional claims in published maps and institutional affiliations.

The original article can be found online at https://doi.org/10.1007/s00338-019-01787-8.

Bernhard Riegl

rieglb@nova.edu

1 Department of Marine and Environmental Science, Nova Southeastern University, 8000 N Ocean Drive, Dania Beach, FL 33004, USA

2 Department of Marine Biology and Ecology, Rosenstiel School of Marine and Atmospheric Science, University of Miami, 4600 Rickenbacker Causeway, Miami, FL 33149-1098, USA

3 Conservation International, Puerto Ayora, Santa Cruz Island, Galapagos, Ecuador

4 Fundacion Charles Darwin, Charles Darwin Research Station, Puerto Ayora, Santa Cruz Island, Galapagos, Ecuador

5 Instituto Nazca de Investigaciones Marinas, Av 8va 1615 calle 20, Salinas, Santa Elena, Ecuador

6 Coral Reef Laboratory, University of Southampton, Southampton, UK 